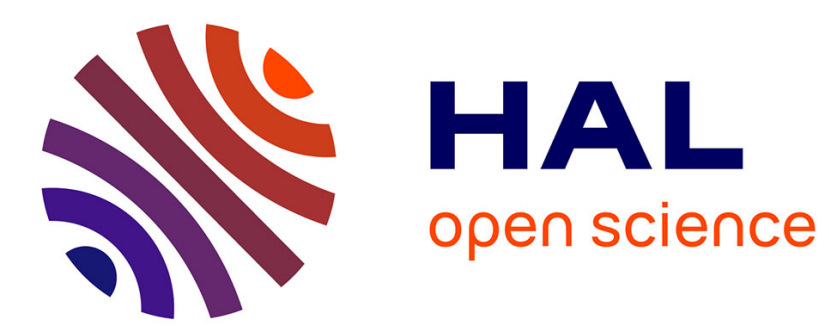

\title{
Ethynylglycine synthon from Garner's aldehyde: a useful precursor for the synthesis of non-natural amino acids
}

\author{
G. Reginato, Patrick Meffre, F. Gaggini
}

\section{To cite this version:}

G. Reginato, Patrick Meffre, F. Gaggini. Ethynylglycine synthon from Garner's aldehyde: a useful precursor for the synthesis of non-natural amino acids. Amino Acids, 2005, 29 (2), pp.81-87. 10.1007/s00726-005-0184-y . hal-02002665

\section{HAL Id: hal-02002665 https://hal.science/hal-02002665}

Submitted on 11 Feb 2019

HAL is a multi-disciplinary open access archive for the deposit and dissemination of scientific research documents, whether they are published or not. The documents may come from teaching and research institutions in France or abroad, or from public or private research centers.
L'archive ouverte pluridisciplinaire HAL, est destinée au dépôt et à la diffusion de documents scientifiques de niveau recherche, publiés ou non, émanant des établissements d'enseignement et de recherche français ou étrangers, des laboratoires publics ou privés. 


\title{
Ethynylglycine synthon from Garner's aldehyde: a useful precursor for the synthesis of non-natural amino acids
}

\author{
Minireview Article
}

\author{
G. Reginato ${ }^{1}$, P. Meffre ${ }^{2}$, and F. Gaggini ${ }^{1}$ \\ ${ }^{1}$ CNR ICCOM, Dipartimento di Chimica Organica "U. Schiff” Università di Firenze, Polo Scientifico, Sesto Fiorentino, Italy \\ ${ }^{2}$ Centre Universitaire de Formation et de Recherche de Nîmes, Site des Carmes, Nîmes, France
}

\begin{abstract}
Summary. The ethynylglycine synthon, namely $(R)$-2,2-dimethyl-3-(tertbutoxycarbonyl)-4-ethynyl-oxazolidine, can be obtained through the synthetic elaboration of naturally occurring serine. This compound has been exploited as a helpful and versatile non-racemic building block to be used for the design and synthesis of biologically important compounds, mainly non-natural $\alpha$-amino acids. Taking advantage of the terminal acetylene moiety several synthetic applications can be designed. Metalation followed by trapping with electrophiles or $\mathrm{Cu} / \mathrm{Pd}$ catalysed coupling with aromatic halogenides are shown to deliver useful precursors of ethynylglycine derivatives. Additions of bimetallic reagents like stannyl- or silylcuprates are useful entries for the regio- and stereoselective functionalization of the lateral chain, aimed at the synthesis of modified vinylglycine precursors.

An overview of our recent work in the field will be given, and the use of ethynylglycine synthon in the synthesis of non-racemic saturated and unsaturated non-natural amino acids will be briefly reviewed.
\end{abstract}

Keywords: Amino acids - Synthesis - Precursors - Organometallics Ethynylglycine

Amino acids have some fundamental biological roles: for instance, they are used as enzyme inhibitors or, more in general, investigated as therapeutic agents, in addition they are important for probing the structural requirements for the bioactivity of numerous peptides and proteins (Barrett, 1985; Andrews and Tabor, 1999). For these reasons, large efforts have been made in recent years to the preparation of homochiral non-natural amino acids (Duthaler, 1994; Ohfune, 1992; Sardina and Rapoport, 1996; Williams, 1989). Several methods have been developed to introduce chirality during the synthesis of a new amino acid. In many cases the requested configuration is provided by the starting material and maintained throughout the synthetic sequence by means of reactions that do not affect the stereocenter. Naturally occurring chiral compounds are often used for this purpose (Coppola and Shuster, 1987), but the synthesis of new useful non-racemic building blocks has also received a large attention.

Research in our laboratories has recently focused on the synthesis of unusual amino acids (Reginato et al., 1997, 1998, 1999; Meffre et al., 1999, 2001; Meffre, 1999; Meffre and Durand, 2002; Dave et al., 2003) and in the course of our studies we reported the first synthesis of ethynyloxazolidine 1 (Fig. 1).

Due to the simultaneous presence of the oxazolidine moiety, that is widely used as synthetic equivalent of $\alpha$ amino acids, and of the unsaturated lateral chain, that consents to several synthetic elaborations, this compound can be considered as a very useful building block for the synthesis of this class of compounds.

Oxazolidine 1 can be easily prepared from Garner's aldehyde 2 (Fehrentz and Castro, 1983; Garner and Park, 1987; Meffre et al., 1994; Dondoni and Perrone, 1997) either by a two steps sequence (Reginato et al., 1995; Cameron and Khambay, 1998; Falorni et al., 1998) via dibromovinyl intermediate (Corey-Fuchs strategy) (Corey and Fuchs, 1972) or via direct aldehyde-to-alkyne onecarbon homologation, using dimethyl 1-diazo-2-oxopropylphosphonate (Ohira reagent) (Ohira, 1989). This phosphonate must be first prepared by reaction of the commercially available dimethyl 2-oxopropyl phosphonate $\mathbf{3}$ and the potentially explosive tosyl azide $\left(\mathrm{TsN}_{3}\right)$. Very 


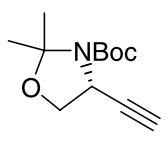

1

Fig. 1. 2,2-Dimethyl-3-(tert-butoxycarbonyl)-4-ethynyloxazolidine

recently, we have improved this procedure and shown that Garner's aldehyde can be directly transformed into compound 1 using a simple one-pot multicomponent process. This involves the in situ formation of dimethyl 1-diazo-2oxopropyl phosphonate from $\mathbf{3}$ and the more friendly 4acetamidobenzene sulfonyl azide (Meffre et al., 2002) (Scheme 1).

Starting with D- or L-serine, compound $\mathbf{1}$ has been obtained in both configurations and its optical purity confirmed $>95 \%$ by ${ }^{\mathbf{1}} \mathrm{H}-\mathrm{NMR}$ analysis of the diastereomeric Mosher's esters prepared from the amino alcohol obtained after deprotection.

Compound 1 has been used as starting material for the first stereoselective synthesis (Meffre et al., 1995 and 1996) of $\alpha$-ethynylglycine 6 as shown in Scheme 2. This unsaturated amino acid, which can be obtained from cul-

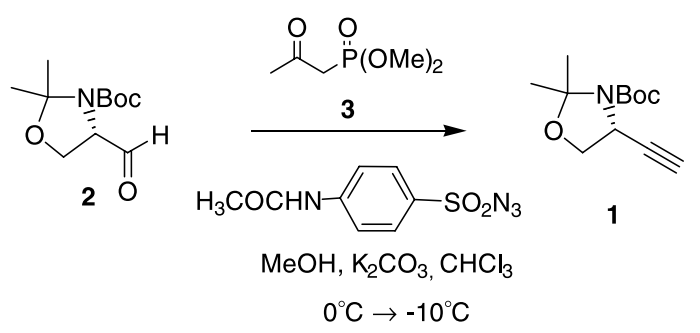

Scheme 1 tures of Streptomices Catenulae, (Kuroda et al., 1980) displays antimicrobial activity against gram-positive bacteria and interacts with D-cycloserine.

While amino acid $\mathbf{6}$ is extremely unstable, oxazolidine $\mathbf{1}$, as its direct precursor, can be conveniently used to prepare stable dipeptide precursors like $\mathbf{7 a}, \mathbf{b}$ (Scheme 3 ) or in the synthesis of optically active ethynylglycine derivatives (Meffre and Le Goffic, 1996). Different functional groups on the terminal position of the lateral chain could be easily introduced, for instance, through metalation and reaction with electrophiles (Corriu et al., 1984). This approach leads to the synthesis of a series of previously unknown compounds 8a-e, as shown in Scheme 4 (Reginato et al., 1995 and 1997; Meffre et al., 1996). Clean silylation and alkylation to $\mathbf{8 a}$ and $\mathbf{8 b}$ were realized using chlorotrimethylsilane, iodomethane, and iodobutane as electrophiles. Reaction with methyl chloroformate and methoxymethyl-chloride gave also good yields, but in these cases, together with $\mathbf{8 c}$ and 8d, variable amounts of by-products 9c, and 9d were obtained. Unfortunately compound $\mathbf{8 e}$, was formed only in low yields hampering a further generalisation of the method. More recently, condensation with aldehydes has been described (Serrat et al., 1999) which provides, after oxidation, acetylenic ketones of structure $\mathbf{1 0}$ (Fig. 2). These compounds have been used in the stereoselective synthesis of novel quinolyl glycines, (Cabarrocas et al., 2000a) enantiomerically pure pyrazolyl- $\beta$-amino alcohols (Cabarrocas et al., 2000b) and quinolyl- $\beta$-amino alcohols (Cabarrocas et al., 2001).

Metalated oxazolidine 1 was also employed in the ethynylation of sugar lactones. A mixture of diastereomeric galactose oxazolidinyl acetylenes 11 (Fig. 3) was formed

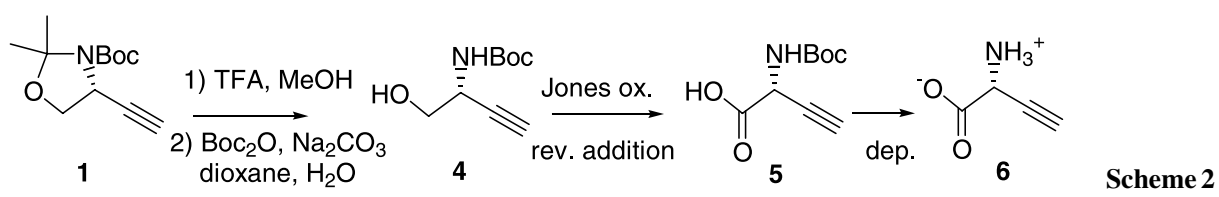

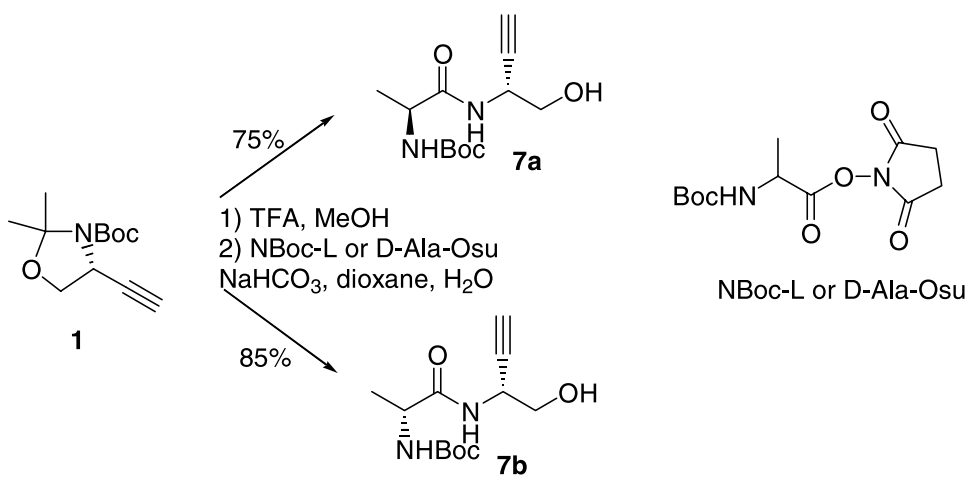




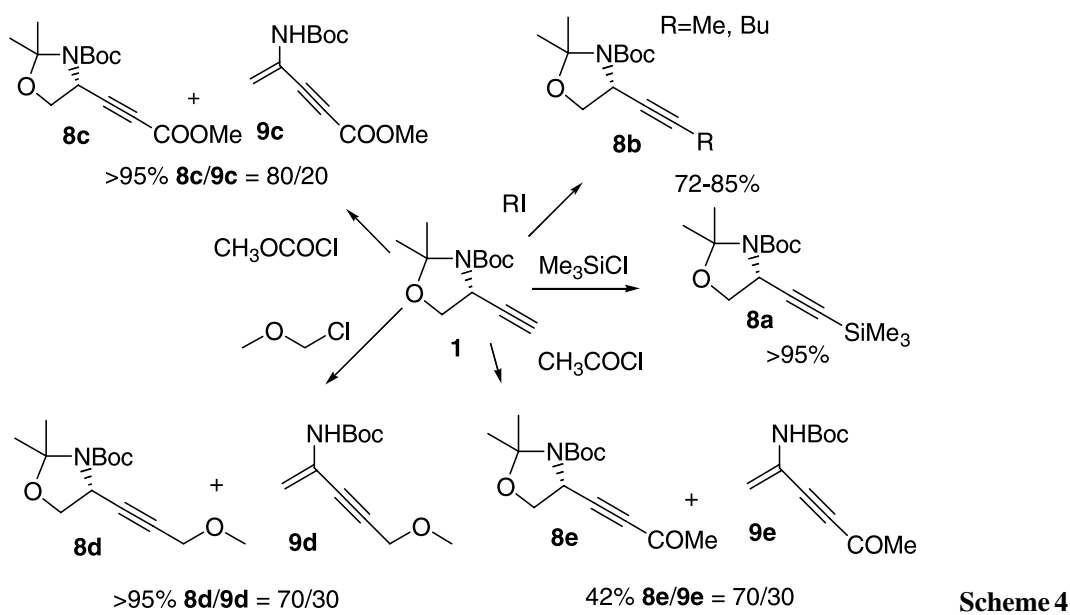

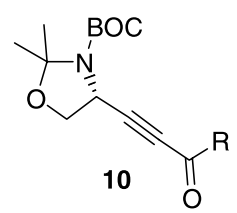

Fig. 2. Useful precursors of enantiomerically pure quinolyl and pyrozolyl $\beta$-amino alcohols and glycines

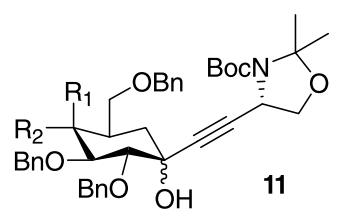

Fig. 3. Ethynylated sugar lactones

and used as intermediates for the synthesis of $\beta$-D-linked methylene isosters of glycosyl serines (Dondoni et al., 2001).

In order to circumvent the problems connected with the formation of by-products, we considered a second, milder approach. Sonogashira coupling between terminal alkynes and aromatic halides in the presence of a copper-palladium catalyst is a well known, efficient, high yielding and chemoselective (Sonogashira et al., 1975) procedure which has been frequently used for introducing differently substituted aromatic rings. This simple approach was applied successfully to prepare compounds $\mathbf{1 2 a}-\mathbf{c}$ (Reginato et al., 1997) as shown in Scheme 5.

The same strategy was used later by other groups. Compound 1 has been coupled with a variety of aromatic and vinylic halides and triflates under Pd catalysis to form a series of aryl-alkynes amino acids precursors like $\mathbf{1 3}$ (Crisp et al., 1997), or an ene-yne aminoacid precursor like 14 (Cameron and Cambay, 1998) (Fig. 4).

We further demonstrated the synthetic versatility of compound $\mathbf{1}$ in the synthesis of vinylglycine precursors, a class of compounds which has received special attention for their biological interest. Addition of metal hydride or dimetallic reagents across the triple bond is known as an easy and practical way for obtaining substituted double bonds. We started to exploit the addition of mixed tributylstannylcuprate 15 (Lipshutz et al., 1989) on to compound $\mathbf{1}$, as it can provide an efficient entry to $\beta, \gamma$-substituted vinyl glycine precursor with a defined $E$ geometry of the double bond (see Scheme 6).

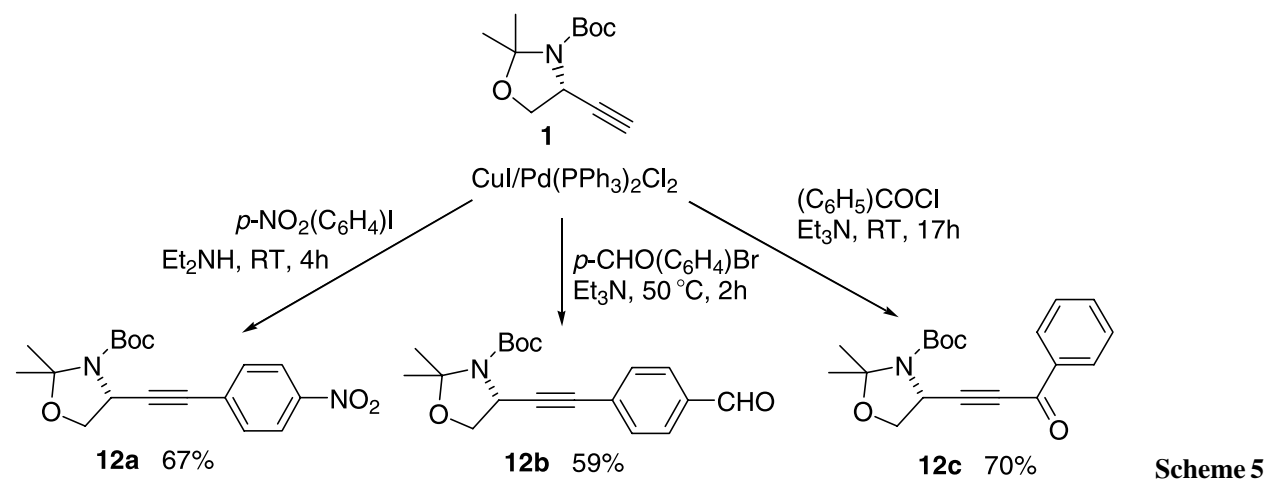




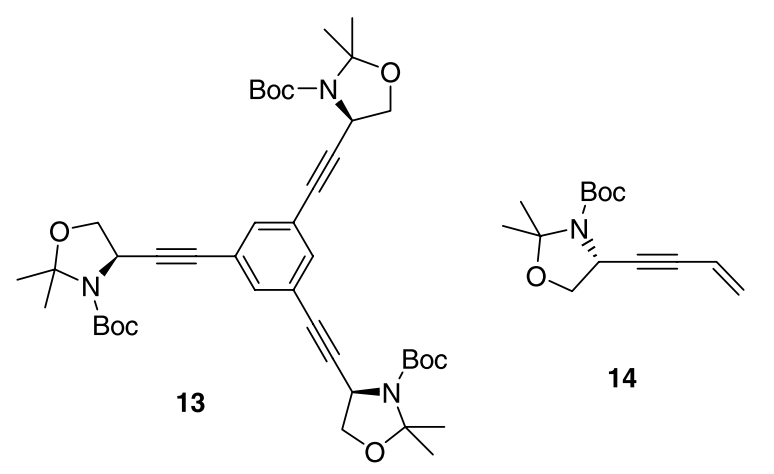

Fig. 4. Aryl-alkynes and ene-yne amino acids precursors

Addition, when followed by hydrolytic work-up, gave $\gamma$ stannylated (E)-ethenyloxazolidine $\mathbf{1 7}$ as a single reaction product in very high yield (Reginato et al., 1997). Trapping of the vinyl copper intermediate with allylbromide or MeI gave the corresponding $\beta$-functionalized vinylstannanes 16a, b. Finally a new series of $\gamma$-substituted $(E)$-ethenyloxazolidine 18a-e resulted from Pd-catalysed Stille coupling (Stille, 1986) of 17 with several electrophiles (Scheme 7) (Reginato et al., 1997).

The same approach was used by Crisp (Crisp et al., 1997) too. In this case the stannylated precursor was prepared through a less selective AIBN initiated hydrostannylation and both $\mathrm{E}$ and $\mathrm{Z}$ isomers were obtained in $85 / 15$ ratio.

Non-racemic amino ketones were also obtained via a high yielding two step Pd catalyzed allylation/Wacker oxidation (Reginato et al., 2000). Compound 19 is a useful intermediate for obtaining 2,6 disubstituted piperidines (Scheme 8).

A similar approach was used also in the synthesis of a new class of silicon containing amino acids. Silicon is an essential element for many biological systems, (Tacke, 1999) and trialkylsilyl chains are known to have hydrophobic properties which might be relevant for biological activity (Tacke, 1985; Tacke and Linoh, 1989) e.g. in the
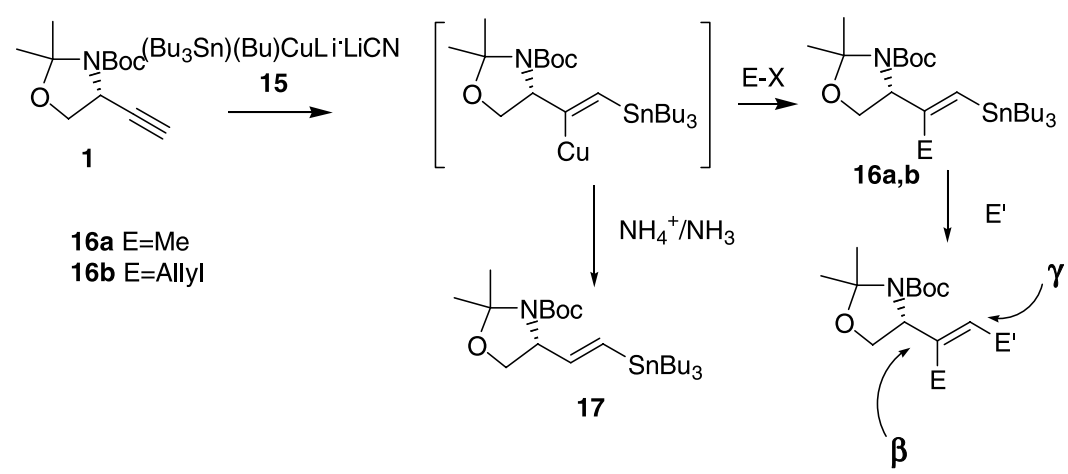

Scheme 6

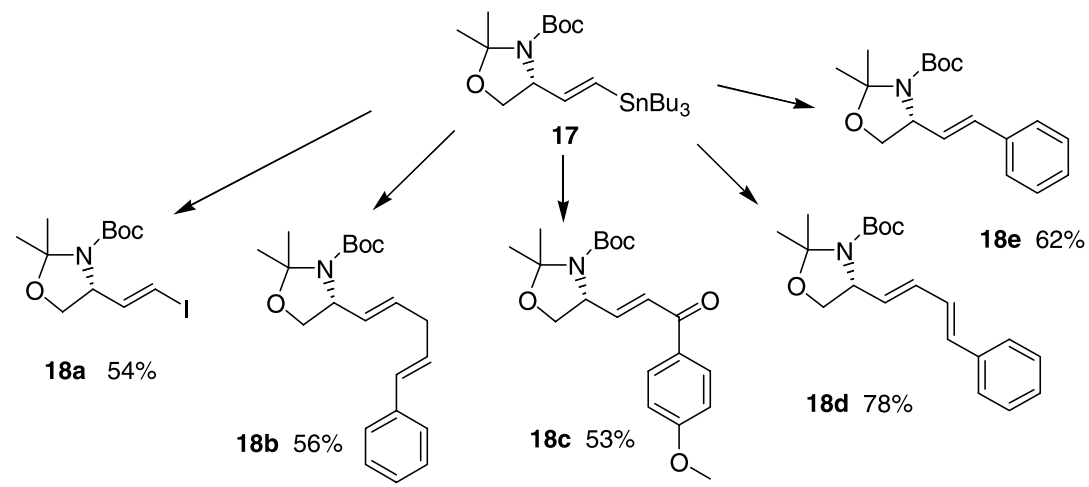

Scheme 7

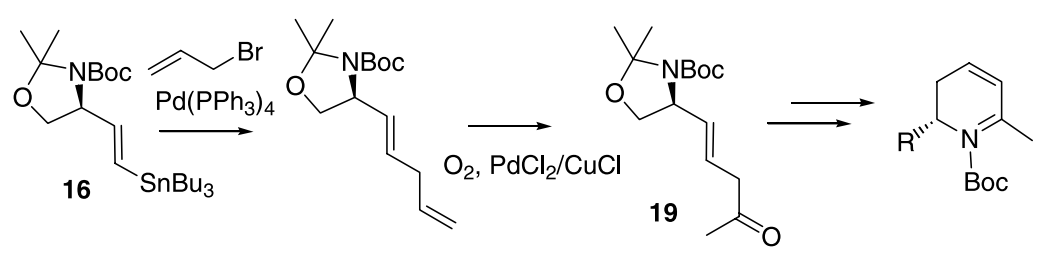

Scheme 8 
field of lipophilic amino acids. Silylated amino acids can also be responsible of enhancing biological activity and proteolitic stability of peptides, as it has already been observed in the search for stable rennin inhibitors (Weidman, 1992). Moreover, because of the high reactivity reported for organosilanes (Fleming et al., 1997), silylated amino acids can be considered as useful optically active starting materials for a variety of synthetic applications.

Addition of trimethylsilylcyanocuprates 20a-c to compound $\mathbf{1}$ and hydrolytic workup gave the corresponding $\gamma$ silylated (E)-ethenyloxazolidine 21a-c (Reginato et al., 1997 and 1999) (Scheme 9), an useful precursor of silicon containing amino acids.

Phenyldimethylsilylcyanocuprate 20b was selected for introducing a dimethylphenylsilyl group which has the advantage of being converted, if necessary, into a hydroxyl group (Fleming et al., 1995). This transformation can find several applications. A recently reported coppercatalyzed procedure was applied (Lipshutz et al., 1998) in this case, which minimized the amount of silyl ligand involved and requires only a small percentages of $\mathrm{CuCN}$, thus making it particular appealing for large scale reactions. Vinylsilane 21b was obtained, using this procedure, in multigram quantities.

Vinylsylanes 21a-c, after reduction of the double bond, hydrolytic removal of the acetonide protecting group and oxidation, afforded a new class of silylated amino acids 22a-c (Scheme 10). The oxidative step was the most chal-

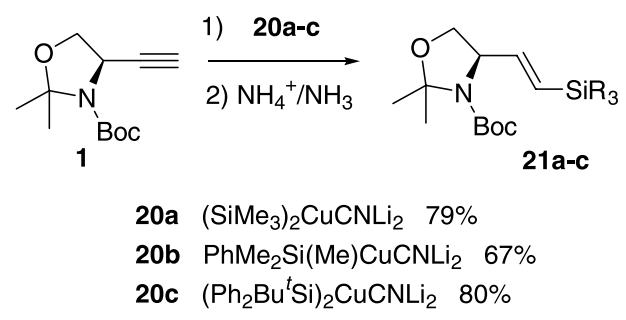

Scheme 9 lenging and the best result was obtained using periodic acid $\left(\mathrm{H}_{5} \mathrm{IO}_{6}\right)$ in the presence of a catalytic amount of chromic anhydride (Zhao et al., 1998).

Remarkably, using this method, unsaturated amino alcohols 23 could also be efficiently oxidized to afford unsaturated amino acid $\mathbf{2 4}$ in satisfactory yield (Reginato et al., 1999) (Scheme 11). The efficiency of the oxidative step in the latter case is in agreement with previous findings that unsaturated amino acids are stabilized by electron donor substituents on the terminal double bond (Beaulieu et al., 1991). The trialkylsilyl groups are thus suitable substituents for stabilizing vinylglycine derivatives. For characterization purposes, crude amino acids were transformed into the corresponding methyl esters and isolated in pure form.

Silylated amino acids were capable of undergoing typical reactions associated with peptide synthesis. For instance 22a, b were coupled with (L)-leucine methyl ester using the diethylcyanophosphonate/diisopropylethylamine (DEPC/DIEA) method to produce dipeptides 25a, b. Under similar conditions disilylated dipeptide 26 was also obtained in good yield (Fig. 5).

Ethynyloxazolidine $\mathbf{1}$ has been also used in the addition of diisopinocamphenyl-borane $\left(\mathrm{Ipc}_{2} \mathrm{BH}\right)$ followed by transesterification with benzpinacol to obtain the alkenylboronic ester 27 (Pietruszka et al., 2003) (Scheme 12), which, although obtained in low yield, has been shown as a promising intermediate for new cyclopropane containing amino acids.

Finally, ethynyloxazolidine $\mathbf{1}$ has been reacted with nitrile oxide to afford isoxazole $\mathbf{2 8}$ that has been transformed into amino acid 29 (Falorni et al., 1998) (Scheme 13). Very recently the same cycloaddition has been carried out by generating nitrile oxides in situ from nitroalkanes, under microwaves irradiation (Giacomelli et al., 2003). This kind of molecules, containing $\alpha$-amino acid with rigid frameworks, are attractive synthetic targets since they can be used as conformationally restricted fragments in
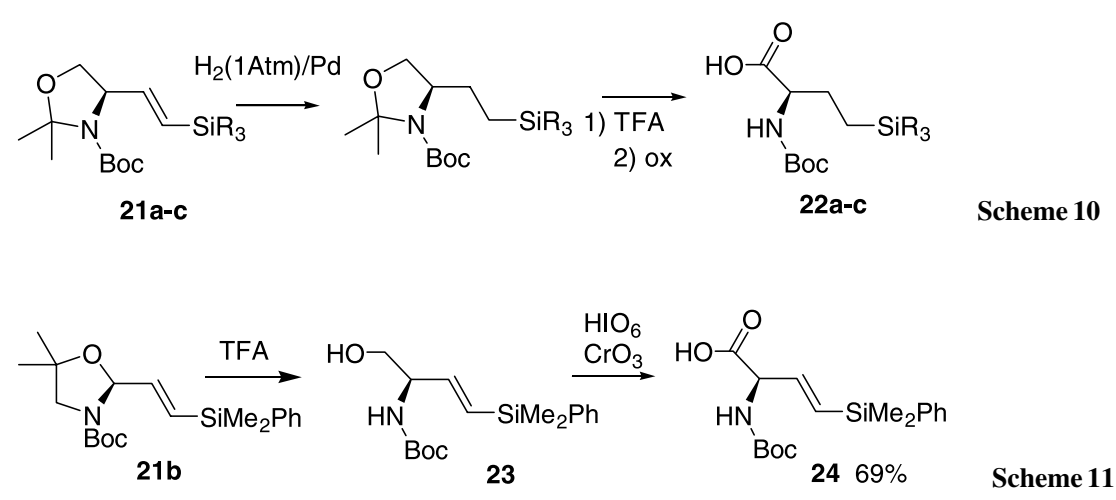


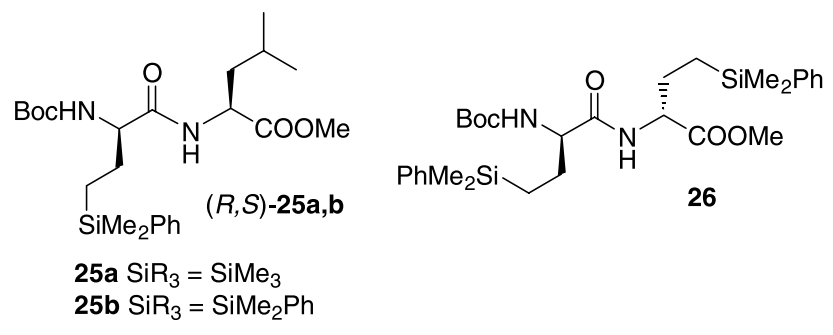

Fig. 5. Silylated dipeptides obtained from silylated amino acids

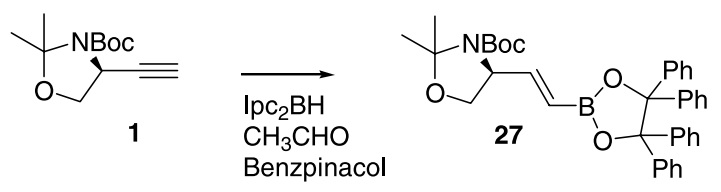

Scheme 12

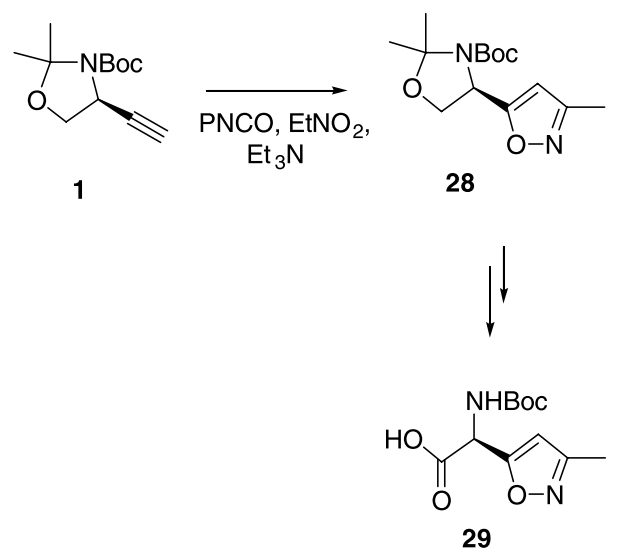

Scheme 13

the design of new peptidomimetic structures with biological activity.

\section{Conclusions}

The use of readily available, enantiomerically pure starting materials has demonstrated its utility as a basis for enantiospecific synthesis. Our contribution in this area has been summarized introducing (R)-2,2-dimethyl-3-(tertbutoxycarbonyl)-4-ethynyloxazolidine (1) as a new, enantiomerically pure, starting material for the synthesis of new optically active amino acids and derivatives.

\section{Acknowledgements}

We thank CNR and CNRS for financial support (Bilateral Agreement of Scientific and Technological Cooperation).

\section{References}

Andrews MJI, Tabor AB (1999) Forming stable helical peptides using natural and artificial amino acids. Tetrahedron 55: 11711-11743

Barrett GC (1985) Chemistry and biochemistry of the amino acids. Chapman and Hall, London

Beaulieau PL, Duceppe JS, Johnson C (1991) Synthesis of chiral vinylglycine. J Org Chem 56: 4196-4204

Cabarrocas G, Rafel S, Ventura M, Villagordo JM (2000a) A new approach toward the stereoselective synthesis of novel quinolyl glycines: synthesis of the enantiomerically pure quinolyl- $\beta$-amino alcohol precursors. Synlett, pp 595-598

Cabarrocas G, Ventura M, Maestro M, Mahia J, Villagordo JM (2000b) Reaction between hydrazines and chiral $\alpha$-acetylenic ketones: synthesis of novel enantiomerically pure pyrazolyl- $\beta$-amino alcohols. Tetrahedron: Asymmetry 11: 2483-2493

Cabarrocas G, Ventura M, Maestro M, Mahia J, Villagordo JM (2001) Stereoselective synthesis of 4-amino-3-hydroxy-2-methylpentanoic acids: stereochemistry of the amino acid occurring in the marine toxin janolusimide. Tetrahedron: Asymmetry 12: 1851-1854

Cameron S, Khambay BPS (1998) Stereospecific synthesis of the amino acid, (S)-2-amino-(Z)-3,5-hexadienoic acid. Tetrahedron Lett 39: $1987-1990$

Coppola GM, Shuster HF (1987) Asymmetric synthesis: construction of chiral molecules using amino acids. Wiley, New York

Corey EJ, Fuchs PL (1972) A synthetic method for formyl $\rightarrow$ ethynyl conversion $\left(\mathrm{RCHO} \rightarrow \mathrm{RCCH}\right.$ or $\left.\mathrm{RCCR}^{\prime}\right)$. Tetrahedron Lett 13: $3769-3772$

Corriu RJP, Huynh V, Moreau JJE (1984) Uses of Si-N bonds in organic synthesis. A direct synthesis of functional protected propargylic primary amines. Tetrahedron Lett 25: 1887-1890

Crisp GT, Jiang YL, Pullman PP, Savi CD (1997) Elaboration of the sidechain of amino acid derivatives by palladium catalysed couplings. Tetrahedron 53: 17489-17500

Dave R, Badet B, Meffre P (2003) $\gamma$-Fluorinated analogues of glutamic acid and glutamine. Amino Acids 24: 245-261

Dondoni A, Perrone D (1997) Organic synthesis, 77th edn. John Wiley \& Sons, New York, pp 64-77

Dondoni A, Mariotti G, Marra A, Massi A (2001) Expeditious synthesis of $\beta$-linked glycosyl serine methylene isosteres ( $\beta$-C-Gly Ser) via ethynylation of sugar lactones. Synthesis, pp 2129-2137

Duthaler RO (1994) Recent developments in the stereoselective synthesis of $\alpha$-amino acids. Tetrahedron 50: 1539-1650

Falorni M, Giacomelli G, Spanu E (1998) Synthesis of new $\alpha$-aminoacids containing the isoxazole moiety. Tetrahedron Lett 39: 9241-9244

Fehrentz B, Castro B (1983) An efficient synthesis of optically active $\alpha$-( $t$-butoxycarbonyl-amino)-aldehydes from $\alpha$-amino acids. Synthesis, pp 676-678

Fleming I, Henning R, Parker DC, Plaut HE, Sanderson PEJ (1995) The phenyldimethylsilyl group as a masked hydroxy group. J Chem Soc Perkin Trans 1, pp 317-320

Fleming I, Barbero A, Walter D (1997) Stereochemical control in organic synthesis using silicon-containing compounds. Chem Rev 97: 2063-2192

Garner P, Park JM (1987) The synthesis and configurational stability of differentially protected $\beta$-hydroxy- $\alpha$-amino aldehydes. J Org Chem 52: 2361-2364

Giacomelli G, Luca LD, Porcheddu A (2003) A method for generating nitrile oxides from nitroalkanes: a microwave assisted route for isoxazoles. Tetrahedron 59: 5437-5440

Kuroda Y, Okuhara M, Goto T, Kohsaka M, Aoki H, Imanaka H (1980) FR-900130, a novel amino acid antibiotic. Discovery, taxonomy, isolation, and properties. J Antibiotics 33: 125-131

Lipshutz BH, Ellsworth EL, Dimock SH, Reuter DC (1989) Transmetalation reactions of higher order cyanocuprates: direct formation of 
trialkyltin cuprates from tin hydrides which bypasses organolithium intermediates. Tetrahedron Lett 30: 2065-2068

Lipshutz BH, Sclafani JA, Takanami T (1998) Silyl cuprate couplings: less silicon, accelerated, yet catalytic in copper. J Am Chem Soc 120: 4021-4022

Meffre P (1999) Synthesis of optically active 2 amino-4-oxobutyric acid and N,O-protected derivatives. Amino Acids 16: 251-272

Meffre P, Durand P (2002) New routes to $\alpha$-amino acids $\beta$, $\gamma$-thienol ether derivatives. Synth Commun 32: 287-296

Meffre P, Goffic FL (1996) $\beta, \gamma$-Alkynyl $\alpha$-amino acids: a synthetic challenge. Amino Acids 11: 313-328

Meffre P, Durand P, Branquet E, Goffic FL (1994) A straightforward synthesis of N-tert-butoxycarbonyl serinate acetonide methyl ester. Synth Comm 24: 2147-2156

Meffre P, Gauzy L, Perdigues C, Desanges-Leveque F, Branquet E, Durand P, Le Goffic F (1995) En route to optically active ethynylglycine derivatives. Tetrahedron Lett 36: 877-880

Meffre P, Gauzy L, Branquet E, Durand P, Goffic FL (1996) Synthesis of optically active $\beta, \gamma$-alkynylglycine derivatives. Tetrahedron 52: 11215-11238

Meffre P, Durand P, Goffic FL (1999) Methyl (S)-2-phatilimido-4-oxobutanoate. Organic Synthesis 76: 123-132

Meffre P, Dave R, Leroy J, Badet B (2001) A concise synthesis of $L-4,4-$ difluoroglutamine. Tetrahedron Lett 42: 8625-8627 corrigendum: ibid, (2002) 43: 6279

Meffre P, Hermann S, Durand P, Reginato G, Riu A (2002) Practical onestep synthesis of ethynylglycine synthon from Garner's aldehyde. Tetrahedron 58: 5159-5162

Ohfune Y (1992) Stereoselective routes toward the synthesis of unusual amino acids. Acc Chem Res 25: 360-366

Ohira S (1989) Methanolysis of dimethyl(1-diazo-2-oxopropyl)phosphonate. Generation of (diazomethyl) phosphonate and reaction with carbonyl compounds. Synth Commun 19: 561-564

Pietruszka J, Witt A, Frey W (2003) Synthesis of "Garner" aldehydederived cyclopropylboronic esters. Eur J Org Chem, pp 3219-3229

Reginato G, Mordini A, Degl'Innocenti A, Caracciolo M (1995) Stereoselective synthesis of $(R)$-(-)-2,2-dimethyl-3-t-butoxycarbonyl-4-ethynyl-oxazolidine: a chiral building block for the synthesis of a new class of substituted alkynes. Tetrahedron Lett 36: $8275-8278$

Reginato G, Mordini A, Caracciolo M (1997) Synthetic elaboration of the side chain of $(R)$-2,2-dimethyl-3-(tert-butoxycarbonyl)-4-ethynyloxazolidine: a new regio- and stereoselective strategy to $\gamma$-functionalized $\beta$-amino alcohols. J Org Chem 62: 6187-6192
Reginato G, Mordini A, Valacchi M (1998) A stereoselective approach to the synthesis of $\gamma$-silylated amino acids. Tetrahedron Lett 39: 9545-9548

Reginato G, Mordini A, Valacchi M, Grandini E (1999) Silylcupration of (R)-2,2-dimethyl-3-(tert-butoxycarbonyl)-4-ethynyloxazolidine: a stereoselective approach to the synthesis of $\gamma$-silylated saturated and unsaturated $\alpha$-amino acids. J Org Chem 64: 9211-9216

Reginato G, Mordini A, Verrucci M, Degl'Innocenti A, Capperucci A (2000) A new approach to non racemic saturated and unsaturated 5-aminoalkyl methyl ketones. Tetrahedron: Asymmetry 11:3759-3768

Sardina FJ, Rapoport H (1996) Enantiospecific synthesis of heterocycles from amino acids. Chem Rev 96: 1825-1872

Serrat X, Cabarrocas G, Rafael S, Ventura M, Linden A, Villagordo JM (1999) A highly efficient and straightforward stereoselective synthesis of novel chiral $\alpha$-acetylenic ketones. Tetrahedron: Asymmetry 10: 3417-3430

Sonogashira K, Tohda Y, Hagihara N (1975) A convenient synthesis of acetylenes: catalytic substitutions of acetylenic hydrogen with bromoalkenes, iodoarenes and bromopyridines. Tetrahedron Lett 16: $4467-4470$

Stille JK (1986) The palladium-catalyzed cross-coupling reactions of organotin reagents with organic electrophiles. Angew Chem Int Ed Eng 25: $508-524$

Tacke R (1985) Organosilicon and bioorganosilicon chemistry; structure, bonding, reactivity and synthetic application. John Wiley \& Sons, New York

Tacke R (1999) Milestones in the biochemistry of silicon: from basic research to biotechnological applications. Angew Chem Int Ed 38: 3015-3018

Tacke R, Linoh H (1989) The chemistry of organosilicon compounds. John Wiley \& Sons, New York

Weidman B (1992) (Trimethylsilyl)alanine: a metabolically stable "bioisostere" for phenylalanine. Chimia 46: 312-313

Williams RM (1989) Synthesis of optically active $\alpha$-aminoacids. Pergamon Press, New York

Zhao M, Li J, Song Z, Desmond R, Tschaen DM, Grabowski EJJ, Reider P (1998) A novel chromium trioxide catalyzed oxidation of primary alcohols to carboxylic acids. Tetrahedron Lett 39: 5323-5326

Authors' address: Dr. Gianna Reginato, ICCOM - CNR, Istituto di Chimica dei Composti Organo Metallici, c/o Dipartimento di Chimica Organica Ugo Schiff, Polo Scientifico - Università degli Studi di Firenze, Via della Lastruccia, 1350019 Sesto Fiorentino, Italy, Fax: +39055 4573580, E-mail: gianna.reginato@unifi.it 